\title{
Radical restructuring in Japan merges science and education
}

[TOKYO] Hopes that an independent ministry for science and technology might emerge from Japan's continuing administrative reform appear to have been dashed.

According to new plans for the restructuring of ministries released last week, Japan will instead create a single Ministry for Culture, Education, Science and Technology from a merger of the present Ministry of Education, Science, Sports and Culture, which oversees research in universities, and the Science and Technology Agency (STA).

The plans have been put forward by a government panel, headed by the prime minister, Ryutaro Hashimoto, responsible for formulating a restructure of ministries planned for 2001. They will be included in an interim report due for publication later this year. A parliamentary decision on the reform plan is expected by next spring.

While rejecting the concept of a ministry of science and technology, intended to bring together existing mission-oriented research programmes and national research centres, the panel recommends promoting Japan's relatively powerless Environment Agency to ministry rank. In an earlier proposal the agency would have been merged with the STA into a Ministry for Science, Technology and the Environment.

Akito Arima, president of the Institute for Physical and Chemical Research, represented the interests of the scientific community

on Hashimoto's panel. Science policy was a rather "marginal issue" in last week's deliberations, he says, and many questions have been left open.

The proposed merger raises several issues, in particular the fate of the missionoriented research bodies attached to STA including the much criticized Power Reactor and Nuclear Fuel Corporation and Japan's National Space Agency. Many feel that these institutions would not fit happily into the education ministry. It will be a difficult task to bring together the "top-down oriented STA with the slow moving, bottom-up oriented ministry of education," says Arima.

Some say that integrating the STA into the ministry of education is the worst scenario possible, because the education ministry's preoccupation with school education could overshadow science and technology. But others see benefits for the scientific community.

Tsutomu Kimura, president of the Tokyo Institute of Technology, says that the merger should make science and technology policy in Japan "more straightforward, efficient and effective". It could resolve some absurd situations that arise because of the bureaucratic wall between the ministry of education and the STA - such as the fact that university researchers receiving large STA grants often have to set up second laboratories outside the university campus because of educa-

\section{New roles for science and technology council}

[TOKYO] Now that proposals for a Japanese science and technology ministry have been dropped, one expectation is that the Council for Science and Technology will take over some of the tasks and functions of the present Science and Technology Agency, possibly including the administration of bigscience programmes. The council is Japan's highest science policy-making body and is chaired by the prime minister.

At present, the STA oversees an important part of Japan's big-science programmes. As most of these - including nuclear fusion and space - have a heavy tilt towards development, many observers wonder how they could fit into the framework of the proposed new education, science and technology ministry. But others say that the proposed reform opens up an opportunity to render existing projects at STA both more cost-efficient and more scientifically rewarding.

In the future, the social sciences and humanities will be added to the council's constituency - which at present covers only natural sciences and engineering. And the council will enjoy a considerably enlarged budget, with more authority and staff of its own, to help it fulfil its originally intended role of coordinating and overseeing all government science and technology. "The fact that the council does not have administrative staff, but relies almost entirely on STA personnel, impinges on its ability to act as a coordinating body," says Wataru Mori, a permanent member of the council.

Akito Arima of the Institute for Physical and Chemical Research hopes that the council can play a more active role in Japanese science policy. At present, the council's main activity is to report on policy questions handed down to it by the prime minister. "A future Council for Science and Technology should play a more active role in policymaking," he says. R.N.\& R.T.

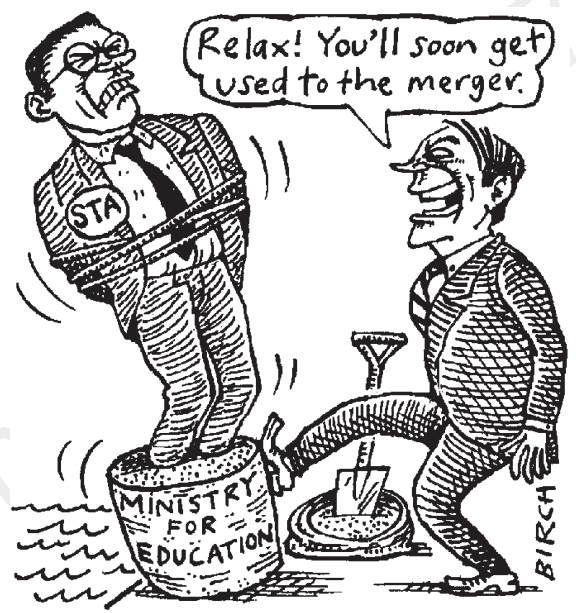

tion ministry regulations.

Kimura also argues that integration with STA may promote the adoption of objective research assessment and evaluation in Japanese universities, which the education ministry has not pushed forward.

Some senior STA officials regret that the agency was not included in the political decision-making which has arranged their fate. They say that this exclusion will be damaging to the morale of the 10,000 staff in STA-related research. They say that there are still many details to be sorted out in the proposed reform.

"We have just seen the birth of the basic law on science and technology last year," comments Kaname Ikeda, director STA's nuclear safety bureau. It will be important to watch how the proposed ministry promotes the "spirit" of that law, Ikeda says

But even within STA there are some who see a positive side to the proposed merger with the education ministry. Breaking down the barriers between national laboratories and universities could help to improve scientific and technical education, they say.

Other details of the restructuring, as well as the fate of national research institutes attached to other ministries - including the laboratories of the Ministry of International Trade and Industry's (MITI) Agency of Industrial Science and Technology — are expected to be discussed at future meetings of the reform panel.

A sensitive issue concerns the administration of Japan's nuclear programme, currently divided between the STA and MITI. Nuclear energy research will probably be handed over to a future Ministry of Industry — a kind of MITI stripped of its industrial policy ambitions. Nuclear safety may be delegated to the proposed environment ministry. 